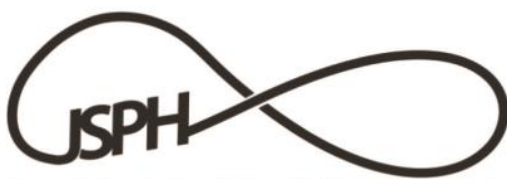

P-ISSN : 2502-7875 E-ISSN : 2527-5879

\title{
MENAKAR KADERISASI KAMMI KOMISARIAT UNIVERSITAS BRAWIJAYA MALANG
}

\author{
Titi Fitrianita ${ }^{1}$, Zulia Antan Ambarsari
}

Jurusan Sosiologi Fakultas Ilmu Sosial dan Ilmu Politik Universitas Brawijaya

${ }^{1}$ Email : titifitrianita@gmail.com

\begin{abstract}
Abstrak
KAMMI (Kesatuan Aksi Mahasiswa Muslim Indonesia) merupakan salah satu organisasi ekstra kampus Universitas Brawijaya yang aktif di dalam kegiatan politik kampus dan mendominasi posisi penting organisasi intra kampus. Keterlibatannya di dalam politik kampus merupakan pengejawantahan usaha menanamkan nilainilai Islam melalui sarana politik. Untuk mempertahankan visi KAMMI dan bentuk organisasi, kaderisasipun dilakukan. Sayangnya, upaya kaderisasi KAMMI tidaklah mudah. Hal ini berkaitan dengan berbagai faktor yang menyebabkan kader KAMMI tetap bertahan atau tidak. Menggunakan metode kualitatif deskriptif tulisan ini bertujuan untuk mengungkap alasan kader KAMMI untuk bertahan atau tidak bertahan di dalam organisasi. Data diperoleh dengan melakukan observasi, wawancara secara mendalam kepada 13 informan dan data sekunder seperti dokumen dan jurnal. Data yang diperoleh dianalisis menggunakan metode induktif dengan triangulasi sebagai metode validitas data. Dari penelitian ini diketahui sistem kaderisasi yang dilakukan oleh KAMMI menggunakan sistem berjenjang dimana untuk naik setiap levelnya membutuhkan pelatihan khusus. Upaya kaderisasi lewat sistem pendidikan berjenjang ini merupakan upaya menghasilkan kader yang loyal dan setia terhadap nilai-nilai di dalam organisasi. Namun ternyata latar belakang keluarga, lingkungan pergaulan, dan pilihan serta harapan individu sangat mempengaruhi keputusan kader untuk bertahan atau tidak bertahan sebagai kader KAMMI. Akhirnya, ketika tidak banyak kader yang bertahan maka KAMMI mengalami kesulitan untuk mempertahankan organisasi dan nilai yang diperjuangkan. Maka memperhatikan 3 faktor tersebut dalam kaderisasi menjadi penting untuk dilakukan KAMMI agar organisasi dapat bertahan.
\end{abstract}

Keywords : Kader, KAMMI, Universitas

\section{MEASURING CADRE OF KAMMI BRAWIJAYA UNIVERSITY BRANCH}

\begin{abstract}
KAMMI is one of off-campus organization which is active in political activities campus and domineering the pivotal position in on-campus organization. Their involvement in politics is an effort to implement Islamic values through political means. To maintain their vision and the existence of their organization KAMMI make a regeneration through recruitment. However, this regeneration is not easy. Using descriptive qualitative approach this paper tries to map KAMMI cadre reasons to stay or not in KAMMI political vision. Data obtained by using observations, in-depth interview to 13 informants and secondary data. Data were analyzed by inductive and using triangulation as a method of data validity. As a result, KAMMI use tiered education system which requires special training to go up any level. This education system is an effort of gaining loyalty and faithfull cadre. However, the cadre family religious background, their social environment, and the personal choices are main factors influencing KAMMI cadre to maintain theirself within organization or to leave the organization. Finally, it is difficult for KAMMI to maintain the organisation and its value when most of their cadre leave the organisation. The 3 factors above urged as a consideration regarding KAMMI cadre organization to make the organisation survives.
\end{abstract}

Keywords : Cadre, KAMMI, University 


\section{LATAR BELAKANG}

Di dalam sejarah gerakan sosial dan politik di Indonesia, pemuda (mahasiswa) tercatat memiliki peran yang sangat penting. Peran pentingnya sebagai oposisi pemerintah yang tugas utamanya adalah sebagai pihak yang melakukan kritik kritis atas kebijakan pemerintah tercatat baik di dalam sejarah politik di Indonesia. Gerakan pelajar seperti Boedi Utomo, Sarikat Islam (SI), Perhimpunan Indonesia (PI) dll pada masa awal kemerdekaan melawan kolonialisme Belanda (Arif, 2016 : 200-201) yang memuncak pada peristiwa Rengasdengklok sebelum Proklamasi Kemerdekaan Indonesia dikumandangkan pada 1945 dan Reformasi 1998 melawan pemerintah Soeharto yang penuh korupsi kolusi dan nepotisme (Arrozy, 2013 : 113-130) menjadi bukti sejarah keterlibatan pemuda yang mengubah secara signifikan politik di Indonesia.

Setelah reformasi terjadi, gerakan pemuda yang melakukan oposisi terhadap kebijakan pemerintah seperti sebelumnya mengalami kelemahan dan lebih berpusat pada urusan agama (religiusitas) (Triyogo, $2018: 3$; Lestari, 2016 : 1). Komunitas-komunitas moral berbasis agamapun terbentuk di universitas. Dalam perjalanannya, gerakan Tarbiyah menjadi gerakan moral yang mendominasi kampus dan menjadi gerakan sosial yang paling berhasil dalam memikat pemuda (Fox, $2004: 1$ ) terutama setelah reformasi. Gerakan ini bertujuan mempromosikan pemahaman agama Islam lebih dalam dan pengenalan nilai serta prinsip Islam ke dalam kehidupan pengikutnya yang bermuara pada terbentuknya komunitas religius (Salman, 2006 : 175-176). Dan untuk mewujudkan hal tersebut, keterlibatan di dalam politik menjadi salah satu cara.

KAMMI (Kesatuan Aksi Mahasiswa Muslim Indonesia) merupakan salah satu organisasi ekstra kampus yang masuk ke dalam gerakan Tarbiyah (Umar, 2014 : 70-71). Organisasi ini mendorong terbentuknya wacana dan praktik Islamisme di dalam kampus. Dan untuk mewujudkan kehidupan kampus (mahasiswa) yang dekat dengan nilai-nilai Islam sesuai yang diidealkannya maka kader KAMMI memobilisisasi diri dan massa dalam politik mahasiswa yang biasa disebut dengan sebutan politik kampus. Politik oleh KAMMI digunakan sebagai alat (sarana) untuk berdakwah (Sudarsono, 2010 : 60). Sebagai implikasinya, tercatat kader KAMMI mampu menjadi pemimpin kampus (Ketua BEM) di hampir 200 kampus nasional karena kemampuannya beradaptasi dengan iklim kampus dan membangun jaringan yang luas karena menggunakan cara persuasif dan aktif (Suseno, $2018: 5-6)$.

Peran KAMMI dalam politik kampus juga dapat memperkuat peran politik Jemaah Tarbiyah pada tingkat kemahasiswaan dan politik nasional. Mayoritas kader KAMMI merupakan anggota Jemaah Tarbiyah yang memiliki hubungan dengan PKS secara jelas berkaitan dengan ideologi. PKS juga memberikan peluang karir politik bagi kader KAMMI. Contoh alumni kader KAMMI yang berhasil meneruskan jenjang politiknya pada PKS ialah Fahri Hamzah selaku mantan ketua KAMMI yang pertama, Andi Rahmad selaku mantan ketua KAMMI yang kedua, dan Haryo Setyoko selaku mantan sekertaris Jenderal KAMMI yang pertama. Kemudian, KAMMI pada umumnya berkembang pesat di kampus-kampus sekuler di Indonesia. (Machmudi, 2006 : 118-124)

Di Universitas Brawijaya, KAMMI memiliki pengaruh yang besar di dalam politik kampus sebagaimana kampus yang ada di Indonesia. Di universitas ini, kader dari KAMMI telah menduduki jabatan Presiden Badan Eksekutif Mahasiswa sejak tahun 2000 hingga 2018, kecuali tahun 2002 dan 2012. Jabatan tersebut merupakan jabatan yang prestise di kalangan mahasiswa. Selain itu, kader organisasi ini juga mendominasi organisasi intra kampus lainnya yaitu DPM (Dewan Perwakilan Rakyat), BEM Fakultas, Lembaga Dakwah Kampus (LDK), dan mengalahkan dominasi organisasi ekstra kampus yang lain seperti HMI (Himpunan Mahasiswa Indonesia), PMII (Pergerakan Mahasiswa Islam Indonesia), dan IMM (Ikatan 
Mahasiswa Muhammadiyah). (Ambarsari, 2018 : 6-8)

Usaha untuk mengambil peran melakukan perubahan tatanan sosial dengan menggunakan prinsip Islam dan menggunakan kekuatan politik untuk mencapainya tidaklah mudah. Di Universitas Brawijaya, KAMMI mengalami persoalan mempertahankan kualitas kader yang dimilikinya meskipun secara kuantitas kader KAMMI bisa diperoleh dengan mudah lewat strategi-strategi perekrutan aktif dan persuasif. Kaderisasi menjadi hal yang penting untuk dilakukan karena kaderisasi merupakan tolok ukur pengembangan organisasi yang juga berarti visi sebuah organisasi bisa bertahan dan disebarluaskan (Al Ayyubi, 2015).

Di dalam pendidikan berjenjang yang menjadi strategi kaderisasi KAMMI untuk mempertahankan keberadaannya sebagai sebuah organisasi sekaligus sebagai usahanya tetap mendominasi organisasi intra kampus rupanya tidak membuat semua kader KAMMI bertahan. Ada banyak faktor yang membuat kader memilih bertahan atau tidak bertahan di dalam KAMMI. Syafiq (2012 : 13) menemukan ketertarikan personal dan kebutuhan afektif akan perasaan aman dan kepastian diri menjadi faktor yang sangat penting mengapa kader KAMMI tetap bertahan di dalam organisasi tersebut. Ikatan organisasi yang dikembangkan berdasarkan nilainilai religius membuat kader mengalami pengalaman persaudaraan yang kuat dan berbeda dengan organisasi lainnya.

Penelitian lain menemukan bahwa hambatan kaderisasi di dalam KAMMI disebabkan oleh faktor eksternal dan internal (Wahyuni, $2013:$ 1). Kader KAMMI yang memiliki lebih dari satu posisi, kurangnya pendanaan kegiatan dan tumpangtindih waktu antara kegiatan intra kampus dan ekstra kampus menjadi faktor internal sulitnya kader KAMMI bertahan. Di sisi lain, faktor eksternal melibatkan kondisi peserta (kader) yang berhubungan dengan pendidikan politik yang digagas oleh KAMMI.

Wahyuni (2013) dan Syafiq (2012) belum mengidentifikasi faktor lain seperti latar belakang keluarga, kesejarahan, keluarga, lingkungan pergaulan, dan pilihan serta harapan individu yang ternyata sangat mempengaruhi keputusan mereka untuk bertahan atau tidak bertahan sebagai kader KAMMI. Tulisan ini berupaya untuk menganalisis faktor apa saja yang membuat kaderisasi KAMMI berhasil atau tidak dengan memetakan alasan kader yang bertahan dan tidak bertahan di KAMMI. Dengan mengetahui faktor yang menyebabkan bertahan atau tidak bertahan di dalam KAMMI diharapkan dapat menjadi jalan masuk mengetahui perspektif pemuda saat ini dalam melihat keterlibatan pemuda di dalam politik.

\section{METODE PENELITIAN}

Penelitian ini menggunakan metode kualitatif deskriptif dimana data berupa narasi lapang digunakan sebagai data primer. Data lapang ini digali menggunakan 2 teknik yaitu wawancara secara mendalam (in-depth interview) kepada 13 orang yang terdiri dari 7 orang kader tidak aktif dan 6 kader aktif KAMMI. Selain itu, data primer juga diambil dengan menggunakan observasi partisipan dimana peneliti bukan hanya mengamati dari jauh namun juga terlibat di dalam kegiatan subjek penelitian. Selain data primer, penelitian ini menggunakan banyak data sekunder. Data sekunder berupa misalnya struktur organisasi dan sejarah organisasi diambil dengan cara memanfaatkan dokumen, arsip, foto, dan buku yang berhubungan dengan fokus penelitian. Data primer dan sekunder yang telah diperoleh lantas dianalisis dengan menggunakan metode analisis induktif. Untuk memastikan keabsahan data yang diperoleh penelitian ini menggunakan teknik triangulasi sumber.

\section{HASIL DAN PEMBAHASAN KAMMI dan Pergerakan Islam}

Kesatuan Aksi Mahasiswa Muslim Indonesia (KAMMI) adalah organisasi mahasiswa ekstra kampus yang berdiri pada tanggal 29 Maret 1998. Awal pembentukan organisasi ini berasal dari ide spontan yang muncul ketika berlangsungnya diskusi-diskusi dalam sidang komisi FSLDK (Forum Silaturahim Lembaga Dakwah Kampus) Nasional ke-10 di Malang pada tanggal 25-29 Maret 1998, tepatnya 
di Universitas Muhammadiyah Malang. Forum tersebut dihadiri oleh aktivis LDK dari berbagai kampus di Jawa, Sumatera, dan Kalimantan dengan jumlah sekitar 200 orang dari 69 LDK yang ada di 64 kampus. (Rahmat \& Najib, 2015 : 44). Sedangkan, literatur lain meyebutkan bahwa forum tersebut dihadiri oleh 59 LDK yang berafialisasi dengan 63 kampus PTN/PTS di seluruh Indonesia dengan jumlah yang sama yaitu sekitar 200 aktivis dakwah kampus (Sudarsono, 2010 : 11).

Pada pertemuan tersebut, mahasiswa yang tergabung dalam LDK merasa bahwa perlu dibentuk suatu wadah baru selain LDK yang dapat menyatukan dan mengkoordinasi berbagai LDK di Indonesia untuk berkonsentrasi perihal agenda politik. Pembuatan wadah baru tersebut didasari atas keprihatinan mendalam mengenai krisis nasional yang sedang terjadi di Indonesia dan bentuk tanggung jawab moral para mahasiswa terhadap penderitaan rakyat, serta bentuk itikad baik untuk berperan aktif dalam proses perubahan dan perbaikan. Sehingga, terbentuklah Kesatuan Aksi Mahasiswa Muslim Indonesia (KAMMI) setelah forum FSLDK ke10 pada tanggal 29 Maret 1998. Kesatuan aksi ini menyatakan menempatkan diri menjadi bagian dari rakyat yang tak terpisahkan dan akan selalu berbuat kebaikan untuk bangsa dan rakyat Indonesia. (Rahmat \& Najib, 2015 : 47)

Penggunaan nama Kesatuan Aksi Mahasiswa Muslim Indonesia (KAMMI) dilandasi oleh dua pertimbangan. Berdasarkan Buku Panduan Acara Musyawarah Daerah I KAMMI di Palembang Sumatera Selatan tanggal 5-6 Desember 1998 dalam Rahmad \& Najib (2015 : 50-51), pertimbangan penggunaan nama KAMMI sebagai berikut:

a. Dalam sejarah Indonesia, gerakan massa yang berhasil adalah gerakan yang memperhatikan atau memiliki basis kultural. Basis kultural di Indonesia ialah Islam, karena mayoritas masyarakat Indonesia adalah muslim. Fenomena dalam masyarakat juga membuktikan bahwa masyarakat lebih mendengarkan arahan ulama daripada arahan pemerintah. Kata-kata ulama juga dapat menjadi legitimasi masyarakat untuk ikut mengambil peran dalam gerakan massa.

b. Pendirian kesatuan ini dilakukan melalui acara FSLDK Nasional X, yang dihadiri oleh mahasiswa-mahasiswa yang aktif dalam kegiatan ke-Islaman. Sehingga, lebih representatif menggunakan label "Muslim Indonesia" daripada Indonesia.

Dalam deklarasi lahirnya KAMMI dinyatakan bahwa KAMMI bukanlah reinkarnasi dari KAMI (Kesatuan Aksi Mahasiswa Indonesia) tahun 1966. Hal ini disebabkan adanya setting politik yang berbeda. Kesamaan yang ada hanyalah berupa misinya yang mengedepankan aspirasi rakyat dan mengantarkan bangsa Indonesia kepada perubahan dan perbaikan. Selain itu, mereka beranggapan bahwa KAMMI tidak lahir dari LDK karena deklarasi dan forum pembentukannya diadakan setelah Muktamar FSLDK Nasional ke-10. (Rahmat \& Najib, 2015 : 52-59)

Dalam upaya melakukan perubahan dan perbaikan ini, KAMMI melaksanakan aksi di daerah maupun pusat. Aksi pusat atau skala nasional pertama dilaksanakan tanggal 10 April 1998 di halaman Masjid Al-Azhar Jakarta. Aksi ini melibatkan sekitar 20.000 mahasiswa (IPB, ITB, UI, UGM, Unair, dll.) dan rakyat Jabotabek. Aksi tersebut menuntut adanya reformasi total (Rahmat \& Najib, 2015 : 82-83). Hal tersebut membuktikan pernyataan Chaplin (2018:9) bahwa lahirnya KAMMI menyebabkan peningkatan aktivisme politik Islam di Indonesia. Kegiatan aksi yang telah dilakukan KAMMI juga memiliki peranan penting dalam pengunduran diri yang dilakukan oleh presiden Soeharto (Hwang, 2010 : 658). Menurut Eep Saiful Fatah dalam Rahmat \& Najib (2015 : 85), keberhasilan KAMMI dalam menggelar aksi-aksi damai karena KAMMI memiliki kemampuan menggabungkan antara dua variabel besar yaitu masjid dan kampus. Mereka muncul dari masjid kampus dan bergerak di masjid kampus. Yang mana pada waktu itu, kampus adalah ruang yang relatif aman untuk bergerak ditengah kokohnya negara. 
Karena perubahan kondisi sosial dan politik, visi misi awal KAMMIpun mengalami perubahan. Perubahan ini terjadi pada Muktamar KAMMI Nasional. Visi awal yang digagas di dalam Muktamar pertama ialah bahwa KAMMI merupakan wadah permanen yang akan melahirkan kader-kader kepemimpinan nasional yang tangguh dalam upaya mewujudkan masyarakat madani di Indonesia (Rahmad \& Najib, 2015: 142). Sedangkan, visi KAMMI saat ini ialah wadah perjuangan permanen yang akan melahirkan kader-kader pemimpin dalam upaya mewujudkan bangsa dan negara Indonesia yang Islami (Pengurus Pusat KAMMI, 2017 : 2). Misi KAMMI yang awalnya hanya berfokus pada upaya perubahan, pelayanan sosial, dan pendidikan politik menjadi bertambah pada bidang dakwah.

Untuk melaksanakan visi dan misi yang telah dibentuk maka perekrutan menjadi hal yang penting untuk dilakukan. Pada periode kepengurusan KAMMI Pusat pada saat ini yaitu tahun 2017-2019, target rekrutmen kader KAMMI ialah 100.000 (Pengurus Pusat KAMMI, 2018). Kaderisasi merupakan hal yang penting bagi KAMMI untuk mewujudkan tujuan mereka dan menjadi cara untuk menyebarluaskan ideologi organisasi.

\section{Metode Kaderisasi KAMMI}

Menurut Mangkubumi dalam Qodir dan Sarbiran (2000 : 145), kaderisasi merupakan suatu siklus yang berputar terus dengan gradasi yang meningkat dan dapat dibedakan dalam tiga komponen utama. Pertama, aspek pendidikan yang bertujuan untuk meningkatkan berbagai pengetahuan kader yang dibutuhkan. Kedua, meliputi penugasan kader seperti pelibatan kader dalam kegiatan-kegiatan organisasi yang bertujuan sebagai latihan pematangan dan pendewesaan kader. Ketiga, berkaitan dengan pengarahan karir kader dengan cara pemberian tanggung jawab lebih besar dalam besar dalam berbagai aspek perjuangan sesuai potensi dan kemampuan yang ada.

KAMMI melaksanakan tiga komponen utama kaderisasi tersebut dengan sistem pendidikan berjenjang yang dimulai pada level komisariat yang merupakan level paling bawah sekaligus ujung tombak kaderisasi di dalam struktur organisasi KAMMI di Indonesia. Sistem pendidikan yang berjenjang tersebut merupakan implementasi dari cetak biru sistem kaderisasi yang sudah disusun yang disebut dengan Manhaj Pengkaderan KAMMI (MPK). Di dalam MPK tersebut tersusun lengkap sistem organisasi yang harus ada di setiap level organisasi dimana MPK biasanya hanya bisa diakses secara bebas oleh kader yang telah menyelesaikan pendidikan terakhir dan mencapai status kader tertinggi.

Struktur KAMMI terdiri dari Pengurus Pusat (PP) yang membawahi Pengurus Wilayah (PW) pada level provinsi. Pengurus Wilayah membawahi Pengurus Daerah (PD) yang berada pada level kota atau kabupaten. Sedangkan PD membawahi komisariat-komisariat. Di daerah Malang ada 2 status komisariat yaitu komisariat penuh dan komisariat persiapan. Komisariat penuh terdiri dari 5 komisariat yang tersebar di beberapa perguruan tinggi besar yang ada di Kota Malang dimana salah satunya adalah Komisariat Universitas Brawijaya (UB) atau yang sering disebut sebagai Komisariat Brawijaya.

Untuk melaksanakan kaderisasi awal di tingkatan komisariat, pengurus komisariat dibantu penuh oleh Pengurus Daerah (PD) dan 2 lembaga di luar struktur organisasi KAMMI yaitu Korps Pemandu Daerah (KPD), Korps Instruktur Daerah (KID) Malang. KPD dan KID bertugas untuk menyediakan pemandu dan instruktur untuk pendidikan berjenjang.

Perekrutan merupakan usaha pertama yang dilakukan oleh Departemen Kaderisasi KAMMI. Di Komisariat UB, Departemen Kaderisasi merupakan bagian dari organisasi yang bertanggungjawab mengemban misi perekrutan atau rekrutmen. Meskipun rekrutmen merupakan tugas utama dari departemen ini namun setiap kader KAMMI memiliki kewajiban untuk memperkenalkan organisasi ini kepada teman kuliah atau adik tingkat. Hal ini bertujuan untuk melakukan regenerasi organisasi dengan meningkatkan jumlah penggerak organisasi. Ada beberapa hal yang biasa dilakukan untuk rekrutmen calon kader KAMMI. 
Pertama, melalui pendekatan personal kader KAMMI kepada calon kader. Target utama sistem rekrutmen ini adalah kader liqo' (kajian rutin) yang dilaksanakan oleh LDK kampus.Mahasiswa yang mengikuti liqo'

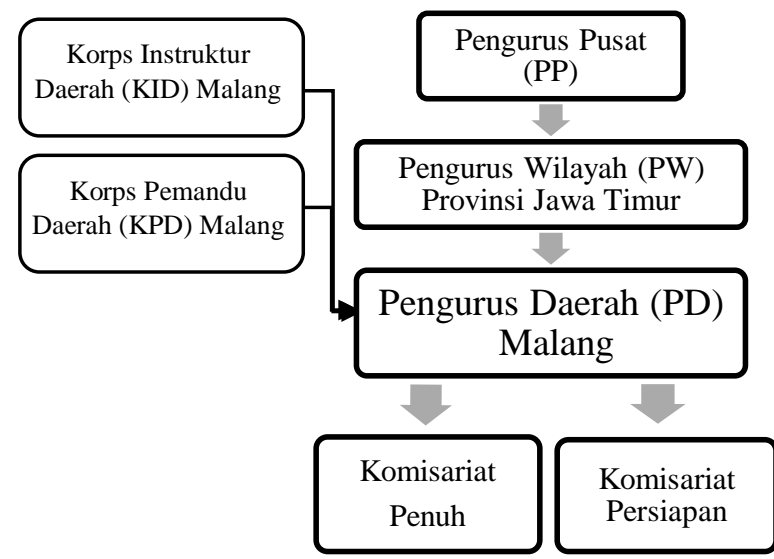

\section{Struktur Organisasi KAMMI}

Sumber: diolah peneliti

merupakan calon kader potensial karena di dalam liqo' tersebut terdapat pemahaman Islam yang mirip dengan yang dibawa di dalam KAMMI. Mengingat banyaknya kader KAMMI yang menjadi pengurus LDK kampus maka lebih mudah mencari calon kader karena telah terdapat persamaan pemahaman Islam. Promosi secara personal juga dilakukan oleh kader KAMMI yang menduduki posisi penting di organisasi intra kampus seperti ketua departemen Ekskutif Mahasiswa yang melakukan perekrutan personal staf yang ada di bawah komandonya.

Kedua, rekrutmen yang dilakukan melalui promosi lewat griya muslim/muslimah. Griya muslim/muslimah merupakan kontrakan di sekitar UB yang dikelola oleh LDK di UB yang telah berafiliasi dengan KAMMI UB. Cara ini biasa dilakukan ketika Sambut Mahasiswa Baru (Samba). Ketika mahasiswa baru melakukan registrasi ulang, kader KAMMI akan secara aktif mempromosikan kontrakan tersebut kepada orang tua mahasiswa baru dan menghubungi mahasiswa baru tersebut melalui telefon setelah terlebih dahulu meminta nomornya untuk bisa bergabung di kontrakan dimana mayoritas penghuni kontrakan adalah kader KAMMI yang juga merupakan kader LDK. Ketika sudah menjadi penghuni kontrakan, anggota kontrakan diwajibkan mengikuti liqo'.
Ketiga, melalui program Pra Dauroh Marhalah (Pra DM). Kegiatan ini dikemas seperti workshop dengan pemateri kader KAMMI yang menduduki posisi penting di kampus seperti Presiden Badan Eksekutif Mahasiswa atau organisasi mahasiswa di bawahnya. Keempat, rekrutmen awal yang paling aktif adalah melalui media sosial dengan menggunakan akun line, grup whatsapp, dan instagram. Di dalam promosi yang dilakukan melalui media sosial ini biasanya berisi testimoni kader KAMMI yang memiliki prestasi di kampus atau menjadi pengurus KAMMI Komisariat UB. Dengan memanfaatkan popularitas dan prestise dari kader-kadernya, KAMMI Komisariat UB hendak membuat citra positif kader-kader yang membuat ketertarikan mahasiswa untuk bergabung dengan KAMMI.

Model perekrutan di atas umumnya masih dilakukan secara sembunyi-sembunyi, sehingga terkadang calon kader tidak memahami sebenarnya mengenai organisasi ini. Tujuannya agar calon kader bersedia dan tidak takut untuk bergabung pada KAMMI, karena terdapat pandangan jelek mengenai organisasi ekstra kampus pada kalangan mahasiswa umum. Target rekrutmen mereka dengan cara ini ialah mahasiswa baru yang belum memahami dengan baik mengenai gerakan mahasiswa di kampus. Namun, seiring beiringnya waktu pola ini berusaha ditinggalkan. Ketua KAMMI Daerah Malang menyatakan bahwa rekrutmen kader harus dilakukan dengan cara terbuka, agar kader KAMMI yang terekrut tidak merasa terbebani dan mempunyai kesadaran untuk melakukan perjenjangan. (Ambarsari, 2018 : 63-68).

Setelah perekrutan dilaksanakan, sistem pendidikan berjenjangpun dimulai. Untuk menjadi kader resmi KAMMI, calon kader harus mengikuti Dauroh Marhalah 1 (DM 1). DM 1 dilaksanakan dengan 2 metode yaitu DM 1 per rayon fakultas (rayon eksakta, sosial, dan agrokompleks) dan DM 1 Akbar yang dilaksanakan untuk seluruh fakultas di UB termasuk yang berada di UB Kediri yang biasanya dilaksanakan setelah penerimaan mahasiswa baru. Jika tidak memungkinkan untuk dilaksanakan atau adanya halangan tertentu, calon kader bisa mengikuti DM 1 di komisariat 
selain UB, namun kader tersebut nantinya akan tetap tercatat sebagai kader Komisariat UB.

Calon kader yang telah menyelesaikan DM 1 disebut kader AB $1^{1}$ (Pengurus Pusat KAMMI, 2006 : 3-6) yang tidak tersertifikasi, yaitu, calon yang dianggap belum memahami penuh organisasi. Untuk mendapatkan status kader AB1 tersertifikasi, kader yang telah lulus DM 1 diwajibkan untuk mengikuti pekan sertifikasi kader yang dilaksanakan oleh pengurus Komisariat UB bekerjasama dengan LSK (Lembaga Sertifikasi Kader) dimana di dalamnya terdapat ujian pengetahuan dan pemahaman kader mengenai materi yang telah didapat di Madrasah KAMMI 1 (MK 1) ditambah dengan manhaj tugas baca serta hafalan juz 30 .

Madrasah KAMMI 1 (MK 1) terdiri dari MK Klasikal dan MK Khos. MK Khos merupakan sarana pembinaan kader secara khusus yang dibentuk seperti liqo' kampus namun menggunakan metode yang berbeda. Sedangkan MK Klasikal merupakan program yang digunakan untuk meningkatkan kualitas pemikiran/ideologi kader KAMMI Brawijaya. Sebagai progam kaderisasi lanjutan, kader harus mengikuti kegiatan kaderisasi lainnya yaitu Dauroh Qur'an dan Mabit (Malam Bina Iman dan Taqwa) yang bertujuan untuk menambah ilmu pengetahuan keagamaan bersama-sama dan menghabiskan malam bersama untuk beribadah.

Sistem pendidikan berjenjang selanjutnya adalah DM 2, DM 3, MK 2, MK 3, Dauroh Pemandu KAMMI (DPMK) dan Training for Instruktur (TFI). DM 2 merupakan diklat yang harus ditempuh untuk mengubah status kader $\mathrm{AB}$ 1 menjadi $\mathrm{AB} 2^{2}$ dan DM 3 untuk mengubah status $\mathrm{AB} 2$ menjadi $\mathrm{AB} 3^{3}$. Kemudian, MK 2

1 AB1 merupakan tipe kader KAMMI yang seharusnya memiliki syakhsiyah islamiyah (kepribadian islam), yang telah siap dan bersedia menjadi penggerak di tengah masyarakat, sehingga dapat menjalankan tugas dakwah dari KAMMI

2 AB2 merupakan tipe kader KAMMI yang seharusnya memiliki syakhsiyah da"iyah muharikah (Kepribadian Dai yang Mampu Menjadi Penggerak). Sehingga mampu menjadi teladan di tengah masyarakat, gerakan islam, dan mampu mengislamisasikan ilmu pengetahuan pada bidangnya dan memelopori solusi Islam dalam berbagai dimensi kehidupan manusia merupakan pendidikan yang bersifat klasikal pada kader $\mathrm{AB} 2$ dan $\mathrm{MK} 3$ untuk kader $\mathrm{AB} 3$. Sedangkan, DPMK dan TFI untuk menghasilkan pemandu dan instruktur kaderisasi KAMMI yang bisa diikuti oleh kader $\mathrm{AB} 2$ dan $\mathrm{AB}$ 3. Kader KAMMI yang telah mendapatkan status $\mathrm{AB} 2$ dapat dicalonkan atau mencalonkan diri menjadi pengurus PD. Sedangkan jika ingin menjadi Ketua PD, kader harus berstatus AB 3. Selain itu kader AB 2 atau AB 3 yang telah lulus DPMK juga dipersiapkan untuk menjadi pemandu MK 1 (Khos dan Klasikal). Para pemandu tersebut akan tergabung ke dalam KPD (Korps Pemandu Daerah) Malang.

Kader AB 2 atau AB 3 yang telah lulus TFI disebut sebagai instruktur yang bisa menjadi bagian dari KID (Korps Instruktur Daerah) Malang. Tugas utama KID adalah sebagai instruktur, merancang acara, dan mengawasi proses dauroh. Instruktur yang menjadi pengawas DM 1 bertugas menilai peserta potensial, mengawasi pelaksanaan dauroh, dan menilai keberhasilan pemateri. Instruktur juga dapat menjadi pemateri pada dauroh KAMMI lainnya, seperti Dauroh Qur'an untuk meningkatkan pemahaman tafsir Qur'an dan memperbaiki cara membaca Qur'an kader KAMMI, Dauroh Ijtimai untuk meningkatkan jiwa sosial kader KAMMI, Dauroh Siyasi untuk meningkatkan wawasan dan skill politik kader KAMMI, dll.

Proses kaderisasi berjenjang ini dilaksanakan sebagai usaha menciptakan sumber daya manusia yang berasal dari dalam organisasi sendiri. Hal ini dilakukan karena awalnya pendidikan berjenjang yang dirancang oleh KAMMI diisi oleh orang-orang yang paham ilmu agama namun tidak paham visi misi KAMMI.

\footnotetext{
${ }^{3}$ AB3 merupakan tipe kader KAMMI yang memiliki syakhsiyah qiyadiyah siyasiyah (Kepribadian Pemimpin Yang Mampu Mengambil Kebijakan). Tipe kader ini harus memiliki kualifikasi keilmuan yang sesuai dengan bidangnya, sehingga mampu menjadi pemimpin gerakan yang menentukan arah gerak dakwah KAMMI yang telah disesuaikan dengan situasi dan kondisi yang telah berkembang. Kader pada tingkat ini bertugas menentukan strategi gerakan KAMMI ke depannya. Strategi yang dimaksud lingkupnya tidak hanya skala daerah atau wilayah, namun pada skala nasional agar dapat mencapai visi dari organisasi ini
} 
Ketika pendidikan berjenjang yang dilaksanakan sebagai bagian dari kaderisasi diisi oleh sumber

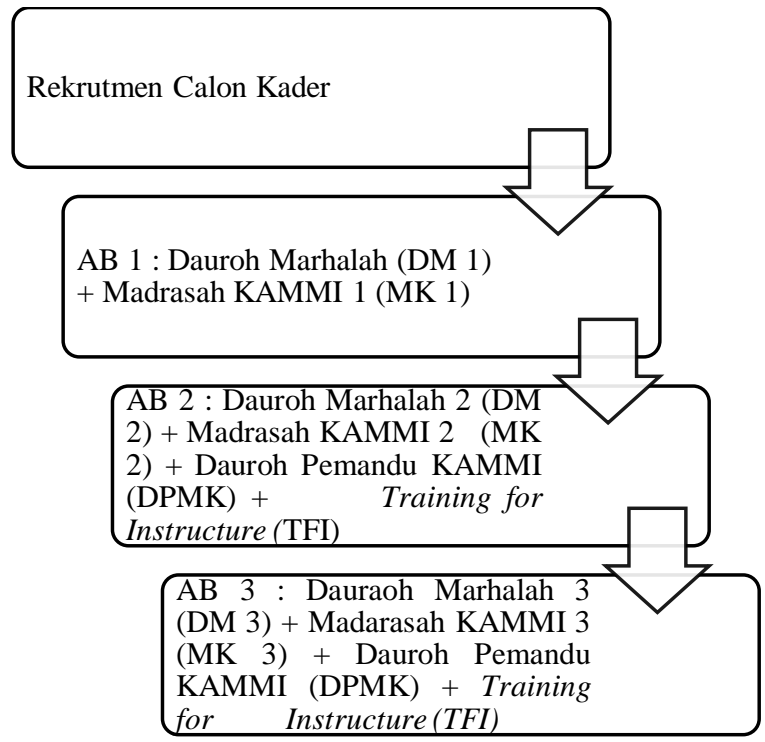

Jenjang Status Kader dan Pendidikan Sumber: diolah peneliti

daya manusia yang berasal dari dalam organisasi, diharapkan menghasilkan kader lanjutan yang memahami betul visi misi KAMMI dan mampu mengejawantahkannya di dalam kehidupan sehari-hari.

Proses perubahan status kader dari calon kader menjadi $\mathrm{AB} 1$, dari $\mathrm{AB} 1$ menjadi $\mathrm{AB} 2$ dan kemudian $\mathrm{AB} 2$ menjadi $\mathrm{AB} 3$ merupakan hal yang mutlak harus segera dilakukan. Misalnya, kader yang berstatus $\mathrm{AB} 1$ diwajibkan segera ikut DM 2 agar statusnya segera berubah menjadi $\mathrm{AB}$ 2. Hal ini dilakukan sebagai upaya mempertahankan status organisasi. Misalnya, untuk menjadi sebuah komisariat penuh, maka disyaratkan adanya minimal 25 kader berstatus AB 1 dan 4 kader $A B$ 2. Jika kurang dari jumlah yang disyaratkan ini maka statusnya akan diturunkan menjadi komisariat persiapan (minimal 1 orang kader $\mathrm{AB} 2$ dan 10 kader $\mathrm{AB}$ 1). Jika jumlah kader yang disyaratkan sangat kurang maka komisariat persiapan bisa dihilangkan.

Hal yang sama juga terjadi pada level PD. Untuk disebut sebagai PD penuh maka di dalamnya harus terdapat minimal 3 orang $\mathrm{AB} 3$, 18 orang $\mathrm{AB} 2$, dan 54 orang $\mathrm{AB} 1$ serta minimal mengelola 2 komisariat. Dengan begitu ketatnya aturan organisasi, kaderisasi menjadi mutlak dilakukan. Selain sebagai upaya untuk menyebarluaskan visi misi, kaderisasi juga dimaksudkan untuk mempertahankan bentuk

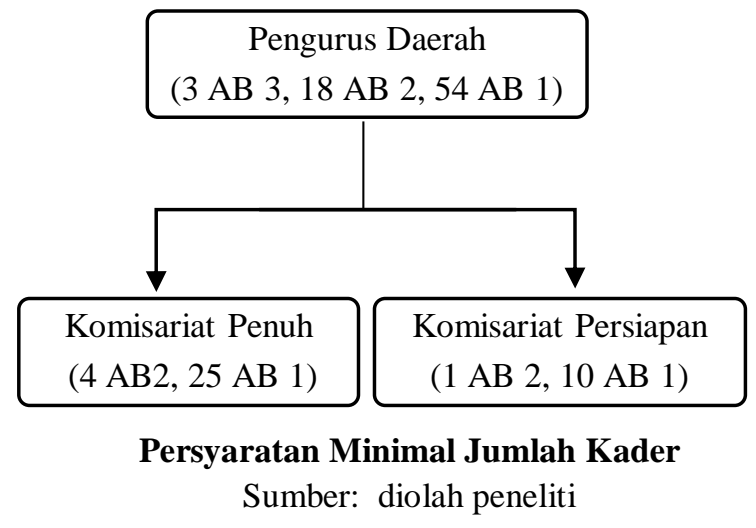

organisasi dengan menyediakan kader yang memenuhi persyaratan di tiap level organisasi di dalam struktur kepengurusan KAMMI.

Untuk menjaring calon kader dalam hal kuantitas, pemosisian kader potensial di posisiposisi strategis di kampus menjadi salah satu cara yang cukup ampuh. Posisi strategis ini diperoleh lewat keikutsertaan KAMMI di dalam politik kampus. Dengan memenangkan posisi strategis di kalangan mahasiswa, visi misi organisasi dapat diwujudkan di satu sisi. Sedangkan di sisi lain upaya untuk mensinergikan politik dengan dakwah yang menjadi ruh dari organisasi ini dengan belajar miniatur kehidupan politik di level negara lewat politik kampuspun dapat diwujudkan

\section{Kader KAMMI Brawijaya}

Kader KAMMI Brawijaya berasal dari background yang bermacam-macam berdasarkan kelompok keagamaan yang diikuti keluarganya maupun pengalaman kader dalam belajar agama sebelum menjadi mahasiswa. Berdasarkan pengamatan peneliti dan hasil wawancara, terdapat kader yang berasal dari keluarga NU, Muhammadiyah, maupun keluarga yang kurang agamis, keluarga mualaf, dan keluarga keturuna Cina. Sehingga, tidak hanya dari background Tarbiyah dan PKS saja yang menjadi kader KAMMI. Kader KAMMI juga berasal dari lulusan yang bermacam-macam seperti SMA, SMK, MA, maupun pondok yang berbasis Tarbiyah maupun lainnya seperti NU atau Salafi. Background yang sama dengan ideologi KAMMI yaitu Tarbiyah dan PKS tidak menjamin kader 
aktif dalam kegiatan kaderisasi. Hal tersebut dikarenakan adanya perbedaan motivasi bergabung dan rasionalitas mengenai kaderisasi pada setiap kader. (Ambarsari, $2018: 77$ )

Klasifikasi kader KAMMI berdasarkan AD/ART terdapat dua jenis, yaitu anggota kehormatan dan anggota biasa. Anggota kehormatan adalah orang yang diangkat karena telah berjasa dalam mengembangkan dan memperjuangkan kemajuan KAMMI, mereka ditetapkan pada forum Musyawarah KAMMI tingkat pusat, wilayah, daerah, maupun komisariat. Sedangkan, anggota biasa ialah mahasiswa muslim Indonesia yang telah memenuhi persyaratan keanggotaan yaitu berusia maksimal 30 tahun dan telah lulus DM 1. Berdasarkan penjenjangannya yang dilakukan secara berkesinambungan anggota biasa KAMMI dapat dibagi menjadi 3 yaitu, AB1, AB2, dan AB3. Klasifikasi ini berdasarkan pada MPK (Manhaj Pengkaderan KAMMI) (Pengurus Pusat KAMMI, $2011:$ 3-6).

Di dalam KAMMI, kader akan mendapatkan pendidikan berjenjang seperti yang telah dijelaskan di pembahasan sebelumnya. Pendidikan berjenjang ini merupakan tahap kedua di dalam kaderisasasi dimana organisasi berupaya melakukan pematangan dan pendewasaan kader (Mangkubumi dalam Qodir \& Sarbiran, 2000 : 145). Di dalam sistem pendidikan berjenjang tersebut, kader yang lebih senior akan melakukan pemetaan potensi yang dimiliki oleh kader yang baru bergabung. Pemetaan potensi kader menjadi dasar bagi pengarahan karir kader. Kader yang memiliki potensi akan diberikan tanggungjawab yang lebih besar di dalam mengemban visi misi organisasi. Proses ini merupakan proses terakhir di dalam kaderisasi.

Setelah resmi sebagai kader, mereka diharapkan untuk aktif di berbagai lembaga yang ada di Universitas Brawijaya. Pengurus akan memetakan potensi dan keinginan individu untuk ditempatkan sebagai pengurus (staf) Komisariat Universitas Brawijaya atau sebagai aktivis yang nantinya akan dicalonkan menjadi pengurus Badan Eksekutif Mahasiswa (BEM) atau Dewan Perwakilan Mahasiswa (DPM). Pengalokasian sumber daya ini dilakukan setelah terlebih dahulu melakukan pemetaan posisi-posisi yang bisa diraih di dalam pemilihan mahasiswa. Dengan sistem pemetaan inilah, KAMMI dapat tetap bertahan dan mempertahankan dominasinya di dalam kampus.

\section{KAMMI : Mereka yang Bertahan}

Terdapat bermacam-macam faktor yang menyebabkan kader KAMMI Brawijaya tetap bertahan dalam organisasi ini melalui keaktifannya dalam kegiatan kaderisasi. Faktorfaktor tersebut berasal dari faktor internal yang berkaitan dengan motivasi maupun faktor eksternal berupa pengaruh dari lingkungan sosial.

Pertama, adanya kesamaan antara ideologi yang dimiliki kader dan KAMMI. Ideologi yang dimaksud ialah ideologi Islam Tarbiyah yang berasal dari keluarga dan lingkungan sosial kader tersebut. Keluarga kader tersebut merupakan kader PKS (Partai Keadilan Sejahtera) atau kader Jemaah Tarbiyah yang mengikuti kegiatan halaqoh.

"Tujuan sebenernya aku butuh wadah, wadah yang menurut aku pas lah dengan ideologi aku bawa dari SMA dan ternyata cocok di KAMMI, oh ya udah, kenapa nggak di KAMMI." (Wawancara HS, 08 Mei 2018)

Kader yang memiliki ideologi Islam Tarbiyah dari lingkungan sosial selain keluarga yaitu kader yang telah menjadi kader liqo' sejak masa SMP/SMA, kader yang merupakan lulusan pondok/SMA berbasis Tarbiyah, dan kader yang telah memiliki pemahaman Islam puritan melalui pembacaan buku. Kesamaan ideologi yang dimiliki kader dan KAMMI menjadikan kader tersebut akhirnya merasa nyaman di KAMMI. Mereka tidak perlu melakukan penyesuaian diri secara signifikan karena merasa berada di lingkungan yang sama.

Kedua, harapan kader untuk belajar agama di KAMMI dan dukungan keluarga. Kader-kader yang memiliki faktor ini juga berasal dari bermacam-macam latar ideologi Islam yang dimiliki. Seperti, NU, Muhammadiyah, Islam kejawen, keluarga mualaf, dan keluarga yang kurang islami. Namun, keluarga mereka 
memberikan kebebasan kepada mereka untuk belajar agama di KAMMI. Kader tersebut merasa bahwa ideologi Islam yang diajarkan KAMMI melalui beberapa perangkat kaderisasinya merupakan hal yang baik. Mereka merasa bahwa perlu memperbaiki diri dalam hal agama sebab sebelumnya mereka kurang mempelajari Islam secara mendalam, sehingga mereka bertahan di KAMMI Brawijaya dan mengikuti beragam kegiatan kaderisasinya, serta menjalani alur perjenjangan kaderisasi yang telah ditetapkan.

Ketiga, kader merasa KAMMI merupakan organisasi ekstra kampus terbaik dibandingkan dengan organisasi ekstra kampus lainnya. Faktor ini cenderung menjadi faktor yang paling dominan pada mayoritas kader KAMMI Brawijaya. Hal ini sering dijadikan sebagai kebanggaan bagi mereka walaupun pada akhirnya juga menyebabkan beberapa permasalahan seperti konflik dengan kader organisasi ekstra kampus lainnya dan bahkan dapat menjadi faktor kader lain untuk tidak bertahan di KAMMI. Mereka merasa bahwa KAMMI merupakan satu-satunya organisasi ekstra kampus yang menjaga nilai-nilai islami. Mereka merasa organisasi ekstra kampus lain yang berbasis Islam juga seperti HMI (Himpunan Mahasiswa Islam) dan PMII (Persatuan Mahasiswa Islam Indonesia) tidak melakukan hal yang serupa dengan yang mereka lakukan. Mereka memiliki aturan cara berkomunikasi antar kader perempuan dan laki-laki, aturan cara berpakaian, aturan cara berperilaku, dll yang lebih ketat dan mengarah pada syariat Islam.

Keempat, kader merasa mendapatkan teman-teman yang baik dan lingkungan yang baik setelah bergabung dengan KAMMI. Hal ini dirasakan oleh mayoritas kader yang bertahan di KAMMI Brawijaya. Model pengkaderan melalui ukhuwah/persaudaraan menjadikan mereka merasa memiliki saudara di tempat perantauan pada masa kuliah. Mereka saling mengingatkan satu sama lain sesama kader dalam hal kebaikan dan perihal amal yaumi/amal ibadah keseharian, seperti sholat wajib 5 waktu, sholat sunnah, membaca Al-Matsurat pada pagi dan sore hari, membaca Alqur'an, berpuasa, dll. Suasana tersebut berusaha dipertahankan oleh kader dengan cara bertahan di KAMMI melalui keikutsertaan kader dalam kegiatan kaderisasi maupun kegiatan KAMMI lainnya. Mereka juga meyakini bahwa mereka akan menjadi orang baik jika teman-teman dan lingkungan di sekitarnya juga merupakan orang baik.

Faktor-faktor yang dijelaskan di atas merupakan faktor kader untuk bertahan di KAMMI Brawijaya. Terdapat kader yang memiliki lebih dari satu faktor pendorong dari keempat faktor tersebut. Namun, dalam bertahan dalam KAMMI pun mereka harus mengorbankan beberapa hal dan menerima beberapa hal yang tidak menyenangkan. Seperti, mengakhiri pertemanan dengan kader organisasi ekstra kampus lain yang tidak pro dengan keberadaan KAMMI Brawijaya, dibully oleh kader organisasi ekstra kampus lainnya, serta dipersulit keikutsertaannya dalam kepanitian di fakultas yang BEMnya tidak dipegang oleh kader KAMMI. Namun, mereka menganggap kesulitan-kesulitan yang mereka hadapi sebagai cobaan dalam berdakwah dan memperjuangkan Islam. Sehingga, tidak terlalu membuat mereka goyah untuk bertahan di KAMMI. Selain itu, faktor-faktor diatas memiliki kekuatan lebih untuk menjadi alasan buat mereka tetap bertahan dalam KAMMI Brawijaya.

\section{KAMMI : Mereka yang Tidak Bertahan}

Kader KAMMI Universitas Brawijaya yang tidak bertahan di KAMMI Brawijaya memiliki tipe bermacam-macam. Terdapat kader yang memutuskan untuk tidak mengikuti kegiatan KAMMI Brawijaya sama sekali, kemudian terdapat yang akhirnya menyatakan diri keluar dari KAMMI Brawijaya, dan bahkan terdapat kader yang akhirnya memutuskan untuk ikut organisasi ekstra kampus lainnya (Ambarsari, 2018 : 31). Perbedaan tipe tersebut tergantung dengan kuantitas dan kekuatan faktor pendorong untuk tidak bertahan di KAMMI.

Pertama, kader merasa tidak cocok dengan ideologi KAMMI. Hal ini disebabkan karena latar belakang ideologi yang dimiliki kader bertentangan dengan KAMMI, seperti Muhammadiyah, NU, Islam kejawen dan latar belakang keluarga yang kurang islami. Kader 
merasa bahwa ajaran Islam dari perangkat kaderisasi KAMMI kurang baik, sebab terdapat beberapa murobbi/pembina liqo' dari kader KAMMI yang melarang kader KAMMI membaca buku-buku yang membahas teori barat seperti buku filsafat. Kader merasa hal ini tidak sesuai dengan yang diajarkan oleh kelompoknya sebelumnya yang membebaskan anggotanya untuk membaca buku dari berbagai aliran pemikiran.

Selain itu, kader yang bukan berasal dari keluarga islami merasa kesulitan beradaptasi pada beberapa dhawabith/ketentuan-ketentuan KAMMI perihal tata cara berpakaian yang harus islami, contohnya pada kader perempuan/akhwat harus memakai rok, jilbab lebar menutupi dada, memakai kaos kaki, dan pakaian yang tidak ketat. Kemudian, dhawabith lainnya seperti pelarangan pacaran, berjabat tangan dengan lawan jenis, berkomunikasi dengan lawan jenis di atas jam malam (20.30 untuk wilayah Malang). Hal-hal tersebutlah yang menjadikan kader memilih tidak bertahan di KAMMI supaya dapat menjalankan kehidupan yang bebas sesuai dengan keinginan mereka.

Kedua, kader tidak menyukai politik kampus. Faktor ini juga berkaitan dengan ideologi KAMMI yang menjadikan politik sebagai alat untuk berdakwah. Hal ini ditentang oleh para kader yang secara internal tidak memiliki ketertarikan dalam hal politik. Kader merasa bahwa KAMMI Brawijaya terlalu memaksakan kadernya untuk dapat berpolitik di dalam kampus.

"Aku merasa mereka kayak dipaksa untuk bisa berpolitik gitu. Berpolitik, trus bisa masuk di lembaga-lembaga kayak BEM, DPM, harus bisa masuk kesitu padahal kan nggak semua orang bisa kesitu dan aku rasa emang KAMMI ini sebenarnya orangorangnya hebat-hebat semua. Cuman apa ya. Mereka terlalu memaksakan kita untuk terjun disini, padahal basicnya mungkin nggak. nggak disitu." (Wawancara FU, 8 Maret 2018)

Selain itu, mereka merasa bahwa politik kampus menyebabkan konflik antarkader organisasi ekstra kampus ketika merebutkan kekuasaan di kampus. Konflik yang terjadi pun bahkan juga berujung pada tindakan kekerasan secara fisik. Kegiatan politik kampus juga menjadikan kader antar organisasi ekstra kampus saling menjatuhkan melalui postingan pada media sosial. Hal ini sering terjadi ketika memasuki masa PEMIRA (Pemilihan Mahasiswa Raya) untuk memilih Presiden dan Wakil Presiden BEM dan DPM tingkat universitas/fakultas. Kader KAMMI Komisariat UB diarahkan untuk bergabung pada kepanitiaan PEMIRA tersebut agar dapat memantau kegiatan dari dalam. Dalam kepanitiaan, kader-kader tersebut diploting pada tempat-tempat tertentu oleh pengurus/kader KAMMI yang berwenang.

Ketiga, kader lebih memilih aktif dalam lembaga intra kampus. Hal ini menjadi salah satu faktor dominan dari mayoritas kader KAMMI yang tidak bertahan di KAMMI. Kesibukan pada lembaga intra kampus seperti BEM, DPM, LSO, dll menjadikan kader tidak mengikuti kegiatan kaderisasi KAMMI maupun kegiatan lainnya. Pada umumnya jadwal kegiatan antara KAMMI dengan lembaga intra sering berbentrokan, sehingga kader terpaksa harus memilih untuk mengikuti kegiatan dalam lembaga intra kampus sebab memiliki amanah di situ. Hal tersebut juga dilakukan untuk mempertahankan kekuasaan yang telah di dapatkan KAMMI Brawijaya di lembaga intra kampus.

Keempat, kader merasa tidak percaya diri, kecewa, atau sakit hati terhadap kader KAMMI lainnya. Dalam KAMMI Brawijaya terdapat kontestasi antarkader yang jarang diperhatikan oleh pengurus KAMMI Brawijaya. Perselisihan kader dalam beradu argumen dan beradu prestasi dapat menjadi pemicu kader untuk tidak bertahan di KAMMI. Hal ini terkadang dianggap biasa, namun terdapat beberapa kader yang akhirnya merasa sakit hati dan kecewa. Rasa sakit hati dan kecewa juga didapatkan kader ketika tidak mendapatkan pengakuan mengenai statusnya sebagai kader KAMMI Brawijaya, mendapatkan perlakuan tidak menyenangkan dari kader lain berupa sindiran ketika tidak menaati dhawabith KAMMI, dll. Selain itu, terdapat juga kader yang merasa tidak percaya diri karena merasa bukan kader yang potensial dalam hal politik. Kader 
yang tidak percaya diri cenderung memilih tidak bertahan di KAMMI karena menganggap bahwa mereka merupakan kader yang tidak dibutuhkan KAMMI. Sehingga, ketika mereka keluar pun tidak akan ada yang akan mencari mereka.

Kelima, kader berhasil/tidak berhasil mencapai harapan awalnya ketika bergabung pada KAMMI Brawijaya dan kader memiliki harapan lain. Harapan awal kader yang tercapai berupa hapan untuk dapat belajar politik dan mendapatkan posisi pada lembaga intra kampus. Harapan yang tidak tercapai berupa keinginan kader untuk dapat belajar agama, sebab kader tersebut merasa terlalu diarahkan dalam bidang yang tidak dia minati yaitu politik. Sedangkan, harapan lain yang peneliti temukan pada kader yang tidak bertahan ialah harapan untuk bergabung dengan organisasi ekstra kampus lain. Kader yang berpindak ke IMM (Ikatan Mahasiswa Muhammadiyah) berharap dapat kembali menjayakan pergerakan mahasiswa Muhammadiyah di kampus, sebab dia juga berasal dari keluarga Muhammadiyah. Kader yang berpindah ke HMI berharap dapat memperdalam pengetahuannya dalam hal keilmuan, sebab dia memiliki minat pada bidang tersebut.

Selain kelima faktor tersebut, terdapat faktor lain seperti kesibukan kader dalam kegiatan akademik dan adanya pengaruh ideologi lain seperti Islam moderat melalui kegiatan di dalam kampus, serta adanya keinginan kader bersama pengurus KAMMI untuk menyembunyikan identitas kader KAMMI agar dapat masuk dalam lembaga intra kampus yang tidak dipengang oleh KAMMI Brawijaya dan menduduki posisi penting di lembaga tersebut. Faktor untuk menyembunyikan identitas ini akhirnya menyebabkan kader tidak mengikuti kegiatan KAMMI Brawijaya sama sekali termasuk kegiatan kaderisasi agar identitasnya tetap terjaga.

Faktor-faktor pendorong kader untuk tidak bertahan di KAMMI yang telah dijelaskan di atas memiliki hubungan satu sama lain. Seperti halnya pada kader yang telah berhasil mencapai harapan awalnya bergabung dengan KAMMI justru memutuskan tidak bertahan di KAMMI sebab dia tidak cocok dengan ideologi KAMMI dan memiliki harapan lain yang berasal dari background keluarganya yang tergabung dalam kelompok Muhammadiyah. Berdasarkan pemetaan peneliti, kader yang memutuskan untuk keluar dari KAMMI ialah kader yang memiliki faktor rasa sakit hati dan kecewa dengan KAMMI Brawijaya, memiliki ketidakcocokan dengan ideologi KAMMI, dan tidak menyukai politik. Kemudian, kader yang berpindah pada organisasi ektra kampus lain ialah kader yang memiliki faktor berupa adanya harapan lain. Sedangkan, kader yang memiliki faktor lain seperti tidak percaya diri, menyembunyikan identitas dan sibuk dalam lembaga intra kampus/kegiatan akademik akan sekedar tidak mengikuti kegiatan KAMMI, tidak sampai menyatakan diri keluar dari KAMMI Brawijaya.

\section{PENUTUP}

Kaderisasi merupakan hal yang penting agar organisasi dapat bertahan. KAMMI menjalankan tujuan organisasinya menyebarluaskan nilai Islam lewat jalur politik kaderisasi menjadi hal yang mutlak dilakukan. Kesamaan ideologi, dukungan keluarga yang memiliki latar yang sama, penilaian yang positif pada organisasi, dan pertemanan yang baik dengan kader yang lain menjadi penyebab utama kader KAMMI bertahan bahkan dengan banyaknya tantangan di sekitar mereka.

Di sisi lain, kaderisasi tidak dapat berjalan dengan baik karena banyak faktor seperti ketidakcocokan ideologi, faktor personal yang tidak tertarik terlibat di dalam politik kampus, latar belakang keluarga yang berbeda pemahaman agama dan ideologi, kekecewaan pada organisasi, dan hubungan tidak harmonis dengan kader KAMMI yang lain menjadi penyebab tidak bertahannya kader KAMMI. Pilihan-pilihan individu (pemuda) dalam keterlibatannya dengan politik yang dalam hal ini adalah politik kampus ternyata melibatkan banyak faktor yang saling tumpang tindih. Dan meskipun KAMMI adalah organisasi ekstra kampus yang dominan namun hal tersebut tidak menjamin mahasiswa yang lain tertarik untuk 
ikut serta menjadi bagian di dalamnya karena faktor-faktor di atas.

\section{DAFTAR RUJUKAN}

Al Ayyubi, S. A. (2015). Peran Kaderisasi Organisasi Ektra Kampus Dalam Meningkatkan Interaksi Sosial dan Kepemimpinan Mahasiswa (Studi Kasus Pada PMII, HMI, dan KAMMI di UIN Sunan Kalijaga). Yogyakarta: UIN Sunan Kalijaga.

Ambarsari, Z. A. (2018). Rasionalitas Sosial Dalam Kegiatan Kaderisasi (Studi Deskripsi Pada Kader Kesatuan Aksi Mahasiswa Muslim Indonesia Komisariat Brawijaya Malang). Malang : Universitas Brawijaya.

Arif, N. (2016). Pergulatan Gerakan Mahasiswa dan Kritik Terhadap Gerakan Moral. Yogyakarta: Fisipol UGM.

Arrozy, a. M. (2013). Antara Jakarta dan Yogyakarta : Gerakan Mahasiswa Islam Pada Masa Orde Baru. Yogyakarta: Universitas Gadjah Mada.

Chaplin, C. (2018). Salafi Activism and the Promotion of a Modern Muslim Identity: Evolving Mediums of Da'wa amongst Yogyakartan University Students. SAGE: South East Asia Research, 26(1), 3-20.

Fox, J. J. (2004). Currents in Contemporary Islam in Indonesia. Harvard Asia Vision 21 (pp. 1-24). Mass: Cambridge.

Hwang, J. C. (2010). When Parties Swing: Islamist Parties. SAGE: South East Asia Research, 18(4), 635-674.

Lestari, S. (2016, Mei Minggu). Penyebaran Gerakan Khilafah di Kampus Menguat Pasca Reformasi. Retrieved from bbc.com:

https://www.bbc.com/indonesia/berita _indonesia/2016/05/160510_indonesia _lapsus_radikalisme_anakmuda_kamp us

Machmudi, Y. (2006). Islamising Indonesia: The Rise of Jemaah Tarbiyah and the Prosperous Justice Party (PKS). Canberra: The Australian National University.
Pengurus Pusat KAMMI. (2011). Manhaj Pengkaderan KAMMI 1427. Retrieved April 10, 2018, from https:// kammimadani.files.wordpress.com/20 11/12/manhaj1427hkammi.pdf

Pengurus Pusat KAMMI. (2017). Draft Anggaran

Dasar Kesatuan Aksi Mahasiswa Muslim Indonesia. Medan.

Pengurus Pusat KAMMI. (2018). Instagram KAMMI Pusat. Retrieved April 10, 2018, from https://www.instagram.com/p/Beb97N WlMUe/?hl=id\&taken-

by=kammi.pusat

Qodir, A., \& Sarbiran. (2000). Kaderisasi Kepemimpinan Agama melalui Pondok Pesantren Al-Munawwir Krapyak Yogyakarta. Jurnal Penelitian dan Evaluasi, 2(3).

Rahmat, A., \& Najib, M. (2015). Gerakan Perlawanan dari Masjid Kampus. Surabaya: Pustaka Saga.

Salman. (2006). The Tarbiyah Movement : Why People Join This Indonesian Contemporary Islamic Movement. Studia Islamika, 171-240.

Sudarsono. (2010). Ijtihad Membangun Basis Gerakan. Jakarta: Muda Cendekia.

Suseno, L. K. (2018). Pola Afiliasi Informal Gerakan Mahasiswa Dengan Partai Politik (Studi Kasus Sistem Kaderisasi Kesatuan Aksi Mahasiswa Muslim Indonesia dengan Partai Keadilan Sejahtera). Semarang : Universitas Diponegoro.

Syafiq, M. (2012). Berbaur Tapi Tidak Lebur : Membentuk dan Mempertahankan Identitas Religius Pada Mahasiswa Aktivis Dakwah Kampus. Jurnal Psikologi : Teori \& Terapan , 1-16.

Triyogo, A. W. (2018, Mei Jumat). Melemahnya Gerakan Mahasiswa Setelah 20 Tahun Refomasi. Retrieved from tempo.co.id: https://nasional.tempo.co/read/109020 5/melemahnya-gerakan-mahasiswasetelah-20-tahunrefomasi/full\&view=ok 
Umar, A. R. (2014). Dinamika Islam Politik Pasca Orde Baru : Kajian Psikoanalisis Lacanian Atas Hubungan KAMMI dan PKS. Jurnal Ulul Albab, 69-96.

Wahyuni, N. I. (2013). Kajian Tentang KAMMI (Kesatuan Aksi Mahasiswa Muslim Indonesia) Sebagai Sarana Pendidikan Politik Bagi Mahasiswa. Semarang: Universitas Negeri Semarang . 